\title{
Reply to a brief comment on the past and present of surgical treatment of cardiac wounds
}

\author{
Erwan Flecher ${ }^{1}$, Alain Leguerrier ${ }^{1}$, and Nicolas Nesseler ${ }^{1}$ \\ ${ }^{1}$ University Rennes Hospital
}

September 11, 2020

\begin{abstract}
Dear Editor, First we would like to thank Dr Lopez de la Cruz for her comments and interest about our recently published article "the odyssey of suturing cardiac wounds: lessons from the past". We highly appreciated and agree with the complements she made especially about Larrey and Milton role in this field. One should also note Theodore Tuffier's attempt at cardiac resuscitation in 1898 in a young man dying on the wards at La Pitié Hospital (Paris) ${ }^{1}$. Although this act was performed on an unwounded heart it adds information about the history of surgical approach in such dramatic condition. We do recognize left anterolateral thoracotomy as the gold standard in an emergency room to treat a penetrating cardiac injury. However a median longitudinal sternotomy may be discussed in our opinion if the patient arrived directly in a cardiac surgery operating theater. The patent presented in our paper was directly brought in our operative theater of cardiac surgery and managed immediately by cardiac surgeons and cardiac anesthesiologists, with a cardiopulmonary bypass ready, dedicated scrub nurses and perfusionist. In such specific conditions a sternotomy may be discussed, depending on the context and the anatomical suspected lesions (it was the option retained in the presented case and the surgical procedure was safely performed with good outcome). Clearly, in a peripheral hospital or at the emergency room sternotomy is not an option to be considered and we agree with Dr Lopez de la Cruz.
\end{abstract}

\section{Reply to a brief comment on the past and present of surgical treatment of cardiac wounds}

Erwan Flécher ${ }^{1}$, Alain Leguerrier ${ }^{1}$, Nicolas Nesseler ${ }^{2}$.

\section{Affiliations}

${ }^{1}$ Department of cardiothoracic and vascular surgery, University Rennes Hospital, INSERM, LTSI - UMR 1099, F-35000 Rennes, France.

2 Department of Anesthesia, University Rennes Hospital, Rennes, France

\section{Corresponding author:}

Pr Erwan Flécher.

Service de chirurgie thoracique et cardio-vasculaire, CHU de Rennes, 2 rue Henri Le Guilloux, 35000 Rennes, France.

Tel: + 33299282 497, Fax: +33299282496.

E-mail :erwan.flecher@chu-rennes.fr.

Dear Editor,

First we would like to thank Dr Lopez de la Cruz for her comments and interest about our recently published article "the odyssey of suturing cardiac wounds: lessons from the past". 
We highly appreciated and agree with the complements she made especially about Larrey and Milton role in this field. One should also note Theodore Tuffier's attempt at cardiac resuscitation in 1898 in a young man dying on the wards at La Pitié Hospital (Paris) ${ }^{1}$. Although this act was performed on an unwounded heart it adds information about the history of surgical approach in such dramatic condition.

We do recognize left anterolateral thoracotomy as the gold standard in an emergency room to treat a penetrating cardiac injury. However a median longitudinal sternotomy may be discussed in our opinion if the patient arrived directly in a cardiac surgery operating theater. The patent presented in our paper was directly brought in our operative theater of cardiac surgery and managed immediately by cardiac surgeons and cardiac anesthesiologists, with a cardiopulmonary bypass ready, dedicated scrub nurses and perfusionist. In such specific conditions a sternotomy may be discussed, depending on the context and the anatomical suspected lesions (it was the option retained in the presented case and the surgical procedure was safely performed with good outcome). Clearly, in a peripheral hospital or at the emergency room sternotomy is not an option to be considered and we agree with Dr Lopez de la Cruz.

References

Anthony R. C. Dobell. Theodore Tuffier's attempt at cardiac resuscitation. Ann Thorac Surg 1993;56:583-4. 